\title{
Pregnancy related breast cancer: report of three cases
}

\section{Zaineb Chatbi*, Saloua Sarsar, Hafsa Taheri, Hanane Saadi, Ahmed Mimoni}

Department of Obstetrics and Gynecology, Mohammed VI University Hospital, Oujda, Morocco

Received: 02 January 2021

Revised: 17 February 2021

Accepted: 19 February 2021

\author{
*Correspondence: \\ Dr. Zaineb Chatbi, \\ E-mail: zaineb.cr@gmail.com
}

Copyright: (c) the author(s), publisher and licensee Medip Academy. This is an open-access article distributed under the terms of the Creative Commons Attribution Non-Commercial License, which permits unrestricted non-commercial use, distribution, and reproduction in any medium, provided the original work is properly cited.

\begin{abstract}
Pregnancy-related breast cancer is defined as breast cancer diagnosed during pregnancy or within a year after delivery. In current report, 3 cases of breast cancer, diagnosed during pregnancy are presented. Different diagnostic challenges, different therapeutic methods and major influences of breast cancer on obstetrical outcomes are also discussed in current report. In current case series, the three patients had ages of 36,40 and 44 years old. They were all diagnosed as having breast cancer during pregnancy. Diagnosis was achieved using imaging, and histopathology through breast biopsy. The histological type was not otherwise specified breast cancer in all three cases. Delivery was vaginal in two cases and through caesarean section in one case. Interruption of pregnancy was performed in one case. A bad prognosis was observed in one patient with death after chemotherapy and surgery, and a favourable evolution was observed in the two other cases. The management of this complex entity must be multidisciplinary.
\end{abstract}

Keywords: Pregnancy-related breast cancer, Obstetrical outcome, Breast cancer

\section{INTRODUCTION}

Pregnancy related breast cancer is a well-known entity that is defined as breast cancer diagnosed during pregnancy or within a year after delivery. It is a rare and complex entity and its management must be multidisciplinary.

Preserving pregnancy, choosing the most suitable treatment for the mother, and maintaining the ovarian function are the main objectives to assure when treating a pregnancy-related breast cancer. ${ }^{1}$

In current report, 3 cases of pregnancy related breast cancer are presented along with a discussion and literature review of the diagnosis, treatment methods and their effect on obstetrical issues, and prognosis of breast cancer during pregnancy.

\section{CASE SERIES}

Current investigation reports three cases of breast cancer that were diagnosed during pregnancy. The management of the three patients was possible due to a multidisciplinary intervention.

\section{Case 1}

A 44 years old woman, with a history of diabetes mellitus under insulin therapy was admitted at 16 gestational weeks for a $2 \mathrm{~cm}$, nodular mass on the left breast, localised on the junction of the two internal quadrants, and axillary adenopathies. A biopsy was performed, revealing a not otherwise specified invasive carcinoma grade 2. On the biological level, CA 15-3 was negative at 11 IU. A conserving breast surgery with lymph nodes dissection was performed, showing at pathological examination: not otherwise specified invasive breast carcinoma, grade 2 , with 4 positive lymph nodes among 
lymph nodes. The tumours did express oestrogenic and progesterone receptors, without hyperexpression of Her-2 receptors. The proliferative index was evaluated at $45 \%$. Surgery was followed by an adjuvant chemotherapy that was performed during pregnancy. The patient was admitted again at 37 weeks for vaginal delivery, with no complication. Follow-up of the patient and the infant showed a good evolution. No signs of metastatic disease or cancer recurrence are observed after duration of 3 years.

\section{Case 2}

A 36 years old woman, with no particular medical history was admitted at 22 gestational weeks for a $10 \mathrm{~cm}$, nodular mass on the left breast associated to axillary adenopathies. A biopsy was performed, revealing a not otherwise specified invasive carcinoma grade 2 (Figure 1). Immunohistochemical exploration revealed absence of hormonal receptors expression and no hyperexpression of Her-2 receptors, CA 15-3 was negative at 11 IU. The patient received neo-adjuvant chemotherapy followed by a radical mastectomy with lymph nodes dissection during pregnancy. The patient had a normal vaginal delivery at 37 weeks, with no complication. Follow-up of the patient and the infant showed a good evolution. No signs of metastatic disease or cancer recurrence are observed after duration of 3 years.

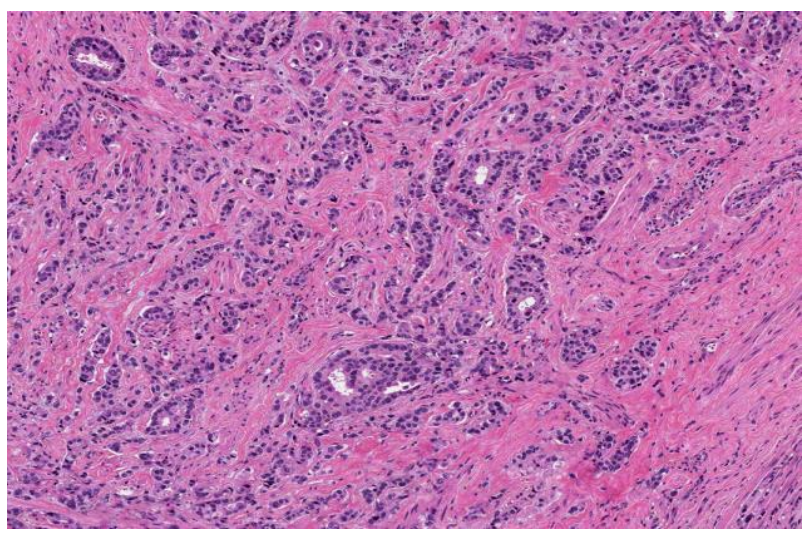

Figure 1: Microphotography showing a

carcinomatous proliferation containing some rare glandular lumens, (HE; 100X).

\section{Case 3}

A 40-year-old woman, with a history of arterial hypertension under treatment was investigated. She was admitted at 25 gestational weeks for a $5 \mathrm{~cm}$, nodular mass on the left breast associated to axillary adenopathies. At breast examination, the skin overlying the nodule was inflamed with a "peau d'orange" appearance. A biopsy was performed, revealing a not otherwise specified invasive carcinoma grade 2 . The patient has made a decision of pregnancy termination. It was performed by caesarean section with bilateral tubal ligation. The patient has received chemotherapy as neoadjuvant treatment before a radical mastectomy with lymph node dissection. Two years after surgery, the patient died.

\section{DISCUSSION}

Pregnancy related breast cancer (PABC) is defined as breast cancer diagnosed during pregnancy or within a year after delivery. It is a well-known entity with the first case report dating back to $1869 .^{2}$ It is still a rare but complex entity and its management must be multidisciplinary. ${ }^{3}$ An association has been found in several studies between breast cancer and pregnancy. Breast cancer is among the most frequently diagnosed cancers during pregnancy with some regional differences. $^{4-6}$ Its occurrence is estimated at 1 in 3000 pregnancies. ${ }^{1}$ This risk reaches its peak 5 years after delivery, following the first term birth. ${ }^{5}$ The majority of cases were described in women with an age of 30 years old or older, and primigravidas younger than 25 years of age show no risk of PABC. ${ }^{6}$ On the pathological level, the predominant histological type is the invasive breast carcinoma not otherwise specified (75-90\%), followed by invasive lobular carcinoma. The occurrence of inflammatory carcinoma is rare and is estimated at around $4 \%{ }^{7}$ Grade II or III carcinomas are the most frequent. ${ }^{8}$ Since there is interference of circulating steroids with the assays used to determine hormonal receptor status, estrogenic and progesterone receptors are usually negative in PABC. ${ }^{8}$ Concerning Her- $2 /$ neu expression, there are no sufficient studies regarding PABC to allow an overall meta-analysis. In general, Her$2 /$ neu is expressed in $10-25 \%$ of mammary carcinomas. ${ }^{2}$ It is important to mention that anti-Her-2 therapy is contraindicated in PABC since many embryonic tissues express this marker. ${ }^{2}$ The clinical diagnosis of breast cancer at an early stage can be difficult because of the denser aspect of the breast since pregnancy and lactation states are associated with glandular and ductal hyperplasias. Nipple discharge is also difficult to detect during lactation. These factors lead in most of the cases to a delay in the diagnosis for up to 7 months. ${ }^{3}$

Analysing cytological samples from breast lumps during pregnancy is no very contributing to the diagnosis since atypical cytomorphologic findings, suggestive malignancy can be also seen in pregnant and lactating women. ${ }^{4}$ A suspicion of PABC should lead to perform a biopsy, which is a sensitive and specific method. However, this may lead to complications such us milk fistula formation and infection, which indicate use of antibiotic and haemostasis. It is important to mention that open biopsies lead to less complications in comparison to core biopsy. Most imaging techniques expose both the mother and the foetus to ionizing radiation. Chest radiograph is considered to be safe if the mother is properly shielded..$^{5} \mathrm{CT}$ scanning of the lower abdomen exposes the foetus to doses reaching $0.089 \mathrm{~Gy}$ and is thus considered no safe. ${ }^{6}$ Two-dimensional mammography can be safe but has a limited contribution to diagnosis. Its sensitivity is below $70 \% .^{7}$ Breast ultrasound is the 
standard method and has high sensitivity and specificity. MRI is an accurate tool concerning both diagnosis and staging. However, it should be avoided since gadolinium is able to cross the placenta and it can potentially harm the foetus. ${ }^{8}$ The treatment of choice of PABC is surgery and chemotherapy, in different protocols (neoadjuvant or adjuvant chemotherapy combined with surgery). In all case, three objectives must be reached while treating a PABC: to preserve pregnancy, to choose the most suitable treatment for the mother, and to maintain the ovarian function. ${ }^{9}$ Pregnancy termination does not seem to improve maternal outcome, information that should be communicated to the patient and her partner. ${ }^{5}$ However, this decision is still personal. Surgery can be performed immediately, but chemotherapy may be delayed until a gestational age safe enough for treatment to be achieved, or even in postpartum period, especially when the diagnosis is made in the late third trimester. ${ }^{10}$ The surgical treatment of choice is either radical mastectomy with axillary lymph node dissection, or breast conserving surgery with axillary lymph node dissection. This later method should be followed by radiotherapy. Both techniques have similar survival rates. ${ }^{11}$

Radiotherapy should be performed with respect of the foetal received dose, proportionately to the gestational age, and can involve the breast, the thoracic wall, and the nodal areas. ${ }^{12}$ Reduction of dose of radiation to the foetus can be achieved by precise radiation techniques, employing extra shielding of the abdomen, or by replacing whole breast therapy with partial breast treatment. ${ }^{12}$ Concerning chemotherapy, efficacy and the risk of toxicity are altered during pregnancy.

During pregnancy, alteration of the half-life of the active form can be partly explained by the increase of hepatic metabolism and renal clearance are both. Other observed alterations during pregnancy are decrease in plasma albumin level and the increase of the presence of amniotic fluid, acting as a third space reservoir. ${ }^{11,12}$ The prognosis of PABC is poor. The 5 year survival is around $52.1 \%\left(80 \% 5\right.$ year survival rate in non-PABC cases)..$^{13}$ However, other studies have reported 5 year survival rate of $75 \%$ in stages II and III PABC cases. ${ }^{13}$ The difference in survival rates can be explained by use of multidisciplinary treatments.

\section{CONCLUSION}

Pregnancy related breast cancer is a rare and complex entity and its management must be multidisciplinary. Among therapeutic goals, preserving pregnancy, choosing the most suitable treatment for the mother, and maintaining the ovarian function are the main ones.

Funding: No funding sources Conflict of interest: None declared

Ethical approval: Not required

\section{REFERENCES}

1. Pavlidis N, Pentheroudakis G. The pregnant mother with breast cancer: diagnostic and therapeutic management. Cancer Treat Rev. 2005;31:439-47.

2. Klotz HA. Ueber mastitis carcinomatosa gravidarum et lactantium, Diss Halle-Wittenberg 1869. Available at: http://opacplus.bsb-muenchen.de/title/BV013545266/ft/bsb10856478? page $=3$. Accessed on 20 December 2020.

3. Knabben L, Mueller MD. Breast cancer and pregnancy. Hormone molecular biology and clinical investigation. De Gruyter. 2017;32(1):1.

4. Stensheim H, Moller B, van Dijk T, Fossa SD. Cause-specific survival for women diagnosed with cancer during pregnancy or lactation: a registrybased cohort study. J Clin Oncol. 2009;27:45-51.

5. Lambe M, Hsieh C, Trichopoulos D, Ekbom A, Pavia M, Adami HO. Transient increase in the risk of breast cancer after giving birth. N Engl J Med. 1994; 331:5-9.

6. Albrektsen G, Heuch I, Hansen S, Kvale G. Breast cancer risk by age at birth, time since birth and time intervals between births: exploring interaction effects. Br J Cancer. 2005;92:167-75.

7. Bonnier P, Romain S, Dilhuydy JM. Influence of pregnancy on the outcome of breast cancer: a caseecontrol study. Societe Francaise de Senologie et de Pathologie Mammaire Study Group. Int J Cancer. 1997;72:720-7.

8. Ring AE, Smith IE, Jones A, Shannon C, Galani E, Ellis PA. Chemotherapy for breast cancer during pregnancy: an 18-year experience from five London teaching hospitals. J Clin Oncol. 2005;23:4192-7.

9. Elledge RM, Ciocca DR, Langone G, McGuire WL. Estrogen receptor, progesterone receptor, and HER$2 /$ neu protein in breast cancers from pregnant patients. Cancer 1993;71:2499-506.

10. Mielke S, Meden H, Kuhn W. Expression of the cerbB-2-encoded oncoprotein p185 (HER-2/neu) in pregnancy as a model for oncogene-induced carcinogenesis. Med Hypotheses. 1998;50:359-62.

11. Saber A, Dardik H, Ibrahim IM, Wolodiger F. The milk rejection sign: a natural tumor marker. Am Surg. 1996;62:998-9.

12. Novotny DB, Maygarden SJ, Shermer RW, Frable WJ. Fine needle aspiration of benign and malignant breast masses associated with pregnancy. Acta Cytol. 1991;35:676-86.

13. Petrek JA. Breast cancer during pregnancy. Cancer. 1994;74(Suppl 1):518-27.

Cite this article as: Chatbi Z, Sarsar S, Taheri $\mathrm{H}$, Saadi H, Mimoni A. Pregnancy related breast cancer: report of three cases. Int J Reprod Contracept Obstet Gynecol 2021;10:1678-80. 